\title{
Influence of hydrogenation conditions on the structural, optical, and magnetic properties of degenerated $\mathrm{Ni} / \mathrm{Al}$ co-doped anatase nanocomposite
}

\author{
A. A. Dakhel ( $\square$ adakhil@uob.edu.bh ) \\ University of Bahrain
}

\section{Research Article}

Keywords: Ni-Al codoped TiO2, Creation of ferromagnetism, hydrogenation,TCO-DMS materials

Posted Date: October 1st, 2020

DOI: https://doi.org/10.21203/rs.3.rs-84110/v1

License: (9) This work is licensed under a Creative Commons Attribution 4.0 International License.

Read Full License 


\title{
Influence of hydrogenation conditions on the structural, optical, and magnetic properties of degenerated Ni/Al co-doped anatase nanocomposite
}

\author{
A. A. Dakhel \\ Department of Physics, College of Science, University of Bahrain, P.O. Box 32038, Sakhir, Kingdom of Bahrain \\ adakhil@uob.edu.bh
}

ORCID: 0000-0001-7251-6055

\section{Abstract}

In the present work, pristine and $\mathrm{Ni}^{2+} / \mathrm{Al}^{3+}$ - codoped anatase $\left(\mathrm{TiO}_{2}\right)$ nanocomposite powders were synthesized by the thermal co-precipitation method. The samples were characterized by several techniques. The X-Ray diffraction (XRD) was used for structural characterization and the optical absorption spectroscopy was used for the optical characterization. The structural/optical studies proved the formation of a substitutional solid solution (SSS). The magnetization measurements were performed to investigate the magnetic properties of the synthesized samples. In the present work, nickel $\left(\mathrm{Ni}^{2+}\right)$ dopant ions were used to introduce stable ferromagnetic (FM) properties into the synthesized anatase, while $\mathrm{Al}^{3+}$ dopant ions were utilized to supply itinerant electrons necessary to support and boost the created FM properties. The roadmap of the present work was to establish the hydrogenation conditions necessary to create ferromagnetic (FM) properties in the host codoped samples and study the effect of hydrogenation temperature on the parameters of the created FM properties, especially the magnetic energy $\left(U_{m a g}\right)$ and saturation magnetization $\left(M_{s a t}\right)$. It was found that the created $\mathrm{FM}$ properties in $\mathrm{Ni} / \mathrm{Al}$-doped $\mathrm{TiO}_{2}$ nanocomposite powder by using the hydrogenation effect could be enhanced and controlled via the temperature of the hydrogenation $\left(\mathrm{T}_{\mathrm{H}}\right)$. The experimental results revealed that $\mathrm{U}_{\text {mag }}$ of $\mathrm{TiO}_{2}: \mathrm{Ni}: \mathrm{Al}$ system increased by $\sim 241 \%$ and the saturation magnetization by $\sim 140 \%$ with increasing of $\mathrm{T}_{\mathrm{H}}$ by $100{ }^{\circ} \mathrm{C}$ (from $400{ }^{\circ} \mathrm{C}$ to $500^{\circ} \mathrm{C}$ ). The obtained saturation magnetization $\left(\mathrm{M}_{\mathrm{sat}}\right)$ of $1.09 \mathrm{emu} / \mathrm{g}$ and magnetic energy $\left(\mathrm{U}_{\mathrm{mag}}\right)$ of $42.6 \mathrm{erg} / \mathrm{g}$ were higher than the previously obtained values for created $\mathrm{Ni}$-doped $\mathrm{TiO}_{2}$ by $\sim 50$ times. Such great novel results were obtained due to dealing with two factors; the $\mathrm{Al}^{3+}$ ions as co-dopant, which can supply an excess of itinerant electrons that boost the S.S Heisenberg interactions in addition to choosing a suitable temperature of hydrogenation.

Keywords: Ni-Al codoped $\mathrm{TiO}_{2}$; Creation of ferromagnetism; hydrogenation; TCO-DMS materials. 


\section{Introduction}

Titanium dioxide belongs to the transparent conducting oxide (TCO) family. It has received great consideration as a multifunctional material widely used for various devices, such as optoelectronics, solar cells, transparent electrodes, gas sensors, and photocatalysis, because of its excellent electrooptical properties [1-6]. Moreover, the developments in the properties of $\mathrm{TiO}_{2}$-based materials are the subject of nowadays.

Pristine Ti dioxide is a wide-band semiconductor with an indirect bandgap of $\sim 3-3.2 \mathrm{eV}[7,8]$. It crystallizes in three possible crystalline structures: anatase [A], rutile [R], and brookite [B] depending on the preparation conditions and temperature $[9,10]$. The photocatalytic, electrical, optical, and other properties of $\mathrm{Ti}$ oxide can be controlled through doping with different ions [11-14]. Besides, the properties of $\mathrm{Ti}$ oxide can be managed by organizing its natural point defects, like oxygen $(\mathrm{O})$ vacancies and Ti interstitials. Moreover, it was found that doping could create exotic properties. For example, doping with transition metal (TM) or rare-earth (RE) ions could create ferromagnetic (FM) properties converting the host $\mathrm{TiO}_{2}$ material into diluted magnetic semiconductors (DMS), which widen its applications.

It is noteworthy that, weak FM behaviour could be easily created in synthesized TCO samples even without doping, which symbolized as a $d^{0} \mathrm{FM}$ phenomenon $[15,16]$. The $\mathrm{d}^{0} \mathrm{FM}$ phenomenon is attributed to the presence of structural point defects like O-vacancies in the nanocrystallites. The Ovacancies can capture itinerant electrons, creating local moments, which lead to some kind of weak magnetic spin-spin $(\boldsymbol{S} . \boldsymbol{S})$ Heisenberg responses [17-21]. The $\mathrm{d}^{0} \mathrm{FM}$ phenomenon was proved to be unstable and could be removed thermally [22].

In the present work, anatase $\mathrm{TiO}_{2}$ nanopowder samples codoped with $\mathrm{Ni}^{2+}$ and $\mathrm{Al}^{3+}$ ions were synthesized to construct DMS. Nickel dopant ions are used to introduce stable ferromagnetic (FM) properties into the anatase powder sample, while Aluminum dopant ions are used to supply itinerant electrons necessary to support and boost the created FM properties. According to the 6-coordination ionic radii table [23], the radii difference between $\mathrm{Ni}^{2+}(0.069 \mathrm{~nm})$ and $\mathrm{Ti}^{4+}(0.06 \mathrm{~nm})$ ions is $\sim 13 \%$ and between $\mathrm{Al}^{3+}(0.054 \mathrm{~nm})$ and $\mathrm{Ti}^{4+}$ is $\sim 10 \%$. Thus, the possible ionic substitutions $\mathrm{Ni}_{\mathrm{Ti}}$ and $\mathrm{Al}_{\mathrm{Ti}}$ cannot cause a significant geometrical distortion in the $\mathrm{TiO}_{2}$ host lattice, according to the Hume-Rothery $(\mathrm{H}$ $\mathrm{R})$ rules. Therefore, ions $\mathrm{Ni}^{2+}$ and $\mathrm{Al}^{3+}$ can easily be doped in the $\mathrm{TiO}_{2}$ crystal forming a substitutional solid solution (SSS). Moreover, it is also possible to believe that some amount of Ni and Al dopant ions might occupy interstitial positions and reside in crystallite boundaries.

The strength of the spin-spin $(\boldsymbol{S} . \boldsymbol{S})$ interaction between $\mathrm{Ni}^{2+}$ dopant ions that could create the FM properties significantly depends on the effective interionic separation (R) as well as the local permittivity of the host $\mathrm{TiO}_{2}$ crystalline medium (ECM) necessary to switch on the $\boldsymbol{S} . \boldsymbol{S}$ Heisenberg interaction. Therefore, it is possible to control the created magnetic properties of the DMSs through 
the dopant kind and concentration and by catalyzing the $\boldsymbol{E C M}$ to permit/boost the $\boldsymbol{S . S}$ interaction. In the present work, the action used to catalyze the $S . S$ interaction is the hydrogenation process. The $\mathrm{H}_{2}$ molecules should be dissociated into $\mathrm{H}$-species under the impact of $\mathrm{Ni}^{2+}$ dopant ions [24]. The $\mathrm{H}$ species can create O-vacancies, which stimulate the $\boldsymbol{E} \boldsymbol{C M}$ to permit the $\boldsymbol{S . S}$ interaction. The Al ions dopant can supply the itinerant electrons that support and boost the $\boldsymbol{S} . \boldsymbol{S}$ interaction. The effect of hydrogenation temperature on the created FM parameters especially the magnetic energy $\left(U_{\operatorname{mag}}\right)$ and saturation magnetization ( $\left.\mathrm{M}_{\mathrm{sat}}\right)$ is the purpose to measure in the present study.

\section{Experimental details}

The road map of the present investigation began with the synthesis of pristine and $\mathrm{Ni} / \mathrm{Al}$-codoped $\mathrm{TiO}_{2}\left(\mathrm{TiO}_{2}: \mathrm{Ni}: \mathrm{Ga}\right)$ nano-powders by thermal co-precipitation method. The starting analar materials for the synthesize were titanium tetrachloride $\left(\mathrm{TiCl}_{4}\right)$ liquid, nickel (II) chloride $\left(\mathrm{NiCl}_{2} \cdot 6 \mathrm{H}_{2} \mathrm{O}\right)$, and aluminum nitride $\left(\mathrm{Al}\left(\mathrm{NO}_{3}\right)_{3}\right)$ (from Sigma-Aldrich Chemical Company). The molar ratios of $\mathrm{Ni} / \mathrm{Ti}$ and $\mathrm{Al} / \mathrm{Ti}$ were $\sim 4.8 \%$. The procedure of synthesis was discussed elsewhere. In brief, the precursor was prepared from a mixture solution of $3 \mathrm{ml} \mathrm{TiCl} 3, \sim 30 \mathrm{ml}$ ethanol, $120 \mathrm{ml}$ bi-distilled deionized water, with the appropriate amounts of $\mathrm{NiCl}_{2} \cdot 6 \mathrm{H}_{2} \mathrm{O}$, and $\mathrm{Al}\left(\mathrm{NO}_{3}\right)_{3}$ in a glass beaker. The solution was kept under magnetic stirring for $\sim 2-3 \mathrm{~h}$ at room temperature, and then the temperature was slowly increased to $\sim 60-80{ }^{\circ} \mathrm{C}$ with continuous stirring until a precipitate powder was obtained. Finally, the powder was flash sintering in a closed oven at $500{ }^{\circ} \mathrm{C}$ for $1 \mathrm{hr}$, followed by a slow cool to the room temperature. The present syntheses lead to the formation of a single phase of the $\mathrm{TiO}_{2}$ structure. $^{2}$ Finally, the powder was palletized under $\sim 8$ tons for characterization. The reference un-doped $\mathrm{TiO}_{2}$ powder was also synthesized by a similar procedure. Amounts from each synthesized fine powder were annealed in the $\mathrm{H}_{2}$-gas atmosphere at the $400{ }^{\circ} \mathrm{C}$ and $500{ }^{\circ} \mathrm{C}$ for $20 \mathrm{~min}$. It is noteworthy that such hydrogenation at high-temperature $500^{\circ} \mathrm{C}$ could not reduce $\mathrm{TiO}_{2}$ to $\mathrm{Ti}$ since $\mathrm{TiO}_{2}$ is very stable oxide and it is difficult to reduce it. The prepared samples were referred to as; $\mathrm{TiO}_{2}-\mathrm{H}, \mathrm{TiO}_{2}: \mathrm{Ni}: \mathrm{Al}-\mathrm{H}$ (for $400^{\circ} \mathrm{C}$ ), and $\mathrm{TiO}_{2}: \mathrm{Ni}: \mathrm{Al}-\mathrm{HH}$ (for $500^{\circ} \mathrm{C}$ ), respectively.

The crystalline structures were investigated by the X-ray diffraction (XRD) method that carried out with a Rigaku Ultima-VI X-ray diffractometer $\left(\mathrm{Cu} K_{\alpha}\right)$. The obtained XRD results were analyzed by the Rietveld profile refinements (RPR) method through a built-in PDXL2 (ver.2.0.3.0) program. The spectral optical properties of the powder samples were measured by Shimadzu UV-3600 double beams spectrophotometer that equipped with an integrating sphere for diffuse reflectance spectroscopy (DRS) measurements in the range of $200 \mathrm{~nm}-830 \mathrm{~nm}$. The magnetic properties of the synthesized samples were measured at room temperature by a vibrating sample magnetometer type VSM-PMC Micro-Mag 3900 . 


\section{Structural analysis}

The crystal structure of the synthesized samples $\left(\mathrm{TiO}_{2}, \mathrm{TiO}_{2}: \mathrm{Ni}: \mathrm{Al}, \mathrm{TiO}_{2}-\mathrm{H}, \mathrm{TiO}_{2}-\mathrm{Ni}-\mathrm{Al}-\mathrm{H}\right.$, and $\mathrm{TiO}_{2}-\mathrm{Ni}-\mathrm{Al}-\mathrm{HH}$ ) were investigated by the X-ray diffraction (XRD) method and the results are shown in Fig.1a. The built-in "Rietveld refinements fitting -PDXL2" program was used to analyze the obtained XRD patterns. The starting models for the structural analysis were anatase $[A]$, rutile [R], and brookite [B]. However, the main crystal structure of the pristine and codoped Ti oxide, shown in Fig.2, was found to be anatase [A] with traces from $[\mathrm{R}]$ and $[\mathrm{B}]$ phases. The extracted lattice parameters given in table: 1 are close to the known parameters of the tetragonal [A] phase of space group (SG) I4 $1 /$ amd of parameters $\mathrm{a}=\mathrm{b}=3.784 \AA$, $\mathrm{c}=9.515 \AA$ [25] or with the JCPDS 21-1272 angles $2 \theta=25.3^{\circ}, 37.7^{\circ}, 47.8^{\circ}, 54^{\circ}, 62.7^{\circ}$. [26]. However, one weak hump was observed at $2 \theta \sim 31.07^{\circ}$ with FWHM $\sim 0.99^{\circ}$ and identified to be (211) reflection of a tiny amount of nano brookite [B] phase (Orthorhombic: Pbca, a=9.184 $\mathrm{A}, \mathrm{b}=5.557 \AA, \mathrm{c}=5.154 \AA$ [25]) of crystallite size $\sim 8.7 \mathrm{~nm}$. In addition, weak humps from a tiny amount of rutile $[R]$ phase (tetragonal: $\mathrm{P} 42 / \mathrm{mnm}, \mathrm{a}=\mathrm{b}=4.5936 \AA$, $\mathrm{c}=2.9587 \AA$ [25]) was also observed in Fig.1a. In general, the anatase phase [A] continued to be almost the unique phase even with co-doping and hydrogenation.

The graphical representation by the Rietveld refinements program for $\mathrm{TiO}_{2}: \mathrm{Ni}: \mathrm{Al}$ sample is demonstrated in Fig.1b, where; the red solid line (up) is the experimental data, the solid blue line (up) is the calculated pattern and the solid pink line (down) is the intensity difference between the experimental and calculated patterns. The Rietveld fitting parameters $\left[R_{w p}(\%)\right.$-weighted profile and $S(\%)$-goodness-of-fit] indicated very well fittings; since $S \sim 1$ [27]. Fig.1b shows the Rietveld refinements fitting for the $\mathrm{TiO}_{2}: \mathrm{Ni}: \mathrm{Al}$ sample of $[\mathrm{A}]$ phase, as an example of an excellent phase fitting $(S=1.16)$. The structural analyses, including the average crystallite size $(C S)$ and the microstrain $(\varepsilon)$, were calculated through the built-in software according to Halder-Wagner (H.W) method[28]:$\left(\beta_{h k l} / \tan \theta_{h k l}\right)^{2}=(k \lambda / D)\left(\beta_{h k l} / \tan \theta_{h k l} \sin \theta_{h k l}\right)+16 \varepsilon^{2}$,where $\theta_{\text {hkl }}$ is the Bragg's angle of (hkl) reflection, $\lambda$ is the $\mathrm{Cu} \mathrm{K} \alpha$ wavelength, $\mathrm{k} \lambda=2.05 \AA$, D is the $\mathrm{CS}, \varepsilon$ is the lattice microstrain, and $\beta_{\mathrm{hkl}}(\mathrm{rad})$ is the peak half-width. Thus, the average CS and $\varepsilon$ could be determined from the straight-line plot of $Y=\left(\beta_{h k l} / \tan \theta_{h k l}\right)^{2}$ vs. $X=\left(\beta_{h k l} / \tan \theta_{h k l} \sin \theta_{h k l}\right)$, as shown in Fig.1c for $\mathrm{TiO}_{2}: \mathrm{Ni}: \mathrm{Al}$ sample. The calculated values of CS and $\varepsilon$ for all studied samples are presented in Table:1. The first observation is that the calculated CS reveals that the synthesized samples consist of nanometric crystallite size in the range of $5-7 \mathrm{~nm}$.

The absence of any XR-reflection related to the pure or compound of $\mathrm{Ni}$ and $\mathrm{Al}$ dopant ions confirms that the dopant ions dissolved in $\mathrm{TiO}_{2}$ lattice and did not aggregate or reacted with the sample's mother ions. Thus, the dopant $\mathrm{Ni}$ and $\mathrm{Al}$ ions formed $\mathrm{SSS}$ within $\mathrm{TiO}_{2}$, which confirms the prediction mentioned in the "introduction" that based on the geometrical H-R rule. 
The XRD patterns of the hydrogenated samples were demonstrated in Fig.1a. It is clear that the hydrogenations $(\mathrm{H}$ and $\mathrm{HH})$ did not change the main phase structure $[\mathrm{A}]$ of any sample. However, a slight boosting of the $[\mathrm{R}]$-phase content at the expense of the $[\mathrm{A}]$ phase was detected to be happening due to the hydrogenation, especially for the $\mathrm{HH}$ sample. The relative ratio of the strongest intensities of $[\mathrm{R}]:(110)$ to $[\mathrm{A}]:(101),\left(\mathrm{I}_{\mathrm{R}} / \mathrm{I}_{\mathrm{A}}\right)$ was $~ 11 \%$ and $14 \%$ for $\mathrm{TiO}_{2}: \mathrm{Ni}: \mathrm{Al}-\mathrm{H}$ and $\mathrm{TiO}_{2}: \mathrm{Ni}: \mathrm{Al}-\mathrm{HH}$, respectively. This result might attribute to the increase in the formed $\mathrm{O}$-vacancies by the increasing of the hydrogenation temperature $\left(\mathrm{T}_{\mathrm{H}}\right)$.

Data analysis revealed that the present codoping caused a decrease in the unit-cell volume since both incorporated $\mathrm{Ni}^{2+}$ and $\mathrm{Al}^{3+}$ dopant ions are smaller than $\mathrm{Ti}^{3+}$ ion. Moreover, the difference in sizes of solute $(\mathrm{Ni}$ and $\mathrm{Al})$ ions and solvent $(\mathrm{Ti})$ ions cause increase in microstrain $(\varepsilon)$ from 0.03 to 0.7 , as given in table: 1 . These variations confirmed the formation of SSS. Another observation is that the hydrogenation slightly increased the unit-cell volume by the formation of O-vacancies.

\section{Optical analysis}

The spectral optical properties of the synthesized powders were studied through the measurements of the diffuse reflectance $R(\lambda)$ spectroscopy (DRS) in the range of $250-800 \mathrm{~nm}$ by utilizing the standard spectral reflectance from $\mathrm{BaSO}_{4}$ powder (supplied by Shimadzu company). The spectral Kubelka-Munk (K-M) absorption function $F(\lambda)$ was calculated by $F(\lambda)=(1-R(\lambda))^{2} / 2 R(\lambda)[29]$, as shown in the inset of Fig.2. The main absorption region $\sim 400-500 \mathrm{~nm}$ was focused to estimate the threshold absorption edge $\left(E_{t h}\right)$, which is almost equivalent to the band gap $\left(E_{g}\right)$ and is given in table:1. The absorption edge of the un-doped $\mathrm{TiO}_{2}$ was found $\sim 3.1 \mathrm{eV}$, which is consent with the known range of bandgaps: 3-3.2 eV [8, 30]. The band gap of host $\mathrm{TiO}_{2}$ suffered narrowing (BGN) due to the codoping by $\mathrm{Ni}^{2+} / \mathrm{Al}^{3+}$ ions, which generated structural point defects including $\mathrm{O}$-vacancies for local charge neutrality. The energy levels of the generated defects lay in the bandgap, close to and merged with the bottom of the host $\mathrm{TiO}_{2}$ conduction band causing a decrease in band gap - Urbach effect [31].

The spectral absorption function $F(\lambda)$ of the hydrogenated samples $\left(\mathrm{TiO}_{2}-\mathrm{H}, \mathrm{TiO}_{2}: \mathrm{Ni}: \mathrm{Al}-\mathrm{H}\right.$, and $\left.\mathrm{TiO}_{2}: \mathrm{Ni}: \mathrm{Al}-\mathrm{HH}\right)$ are shown in Fig.2. It is clear that the hydrogenation introduced hefty changes inside the bandgap of codoped $\mathrm{TiO}_{2}$. Fig.2 reveals that the bandgap of the hydrogenated codoped $\mathrm{TiO}_{2}$ is substantially filled with energy levels of the created defects. Moreover, the hydrogenation enhanced the absorption $F(\lambda)$ in the high-wavelength (NIR) part of the absorption spectrum of the doped samples, so that $F(\lambda)$ is directly proportional to $\lambda$ according to the relation, $F(\lambda) \sim \lambda^{p}$ (where $p>$ 0 ), as shown in fig.3 “* “. Such behaviour is usually attributed to the absorption of free-carriers (itinerant electrons) and attributed by the highly generated O-vacancies that noticeably increased the free-carrier concentration [32 - 36]. 
The hydrogenation creates dense O-vacancies and itinerant electrons in doped $\mathrm{TiO}_{2}$, which causes an increase in the optical absorption $\mathrm{A}(\lambda)$ in the NIR spectral region (fig.3). Data on table:1 shows that the hydrogenation of un-doped and the co-doped $\mathrm{TiO}_{2}$ samples shifted their threshold edges $\left(E_{t h}\right)$ to higher energies of different magnitudes. For the un-doped $\mathrm{TiO}_{2}-\mathrm{H}$ sample, the blue shift in $E_{t h}$ is attributed to the reduction in the density of structural defects: imperfection, dislocation, dangling bonds, etc., causing cutback in the Urbach tail that increased in $E_{t h}$. However, for co-doped $\mathrm{TiO}_{2}$ sample, the blue shift in the measured optical bandgap is attributed mostly to the increase in carrier concentration following the Moss-Burstein (B-M) mechanism [37]. During the hydrogenation process of the host $\mathrm{TiO}_{2}$ under the impact of dopant $\mathrm{Ni}^{2+}$ ions, some $\mathrm{H}_{2}$ molecules should be dissociated into $\mathrm{H}$-species (atoms/ions) [24], which, in turns removed some structural oxygen creating/densifying Ovacancies with itinerant electrons. Dopant ions play the role of the internal catalyst in the dissociation of $\mathrm{H}_{2}$ molecules.

It is worth noting that such an increase in free (itinerant) electrons concentration should support the $E C M$ to switch on the $\boldsymbol{S} . \boldsymbol{S}$ interaction and, hence create/enhance the FM properties.

5.

\section{1- Investigation of the as-prepared samples:}

The pristine anatase $\mathrm{TiO}_{2}$ was known to have diamagnetic (DM) properties [38, 39]. However, the synthesized un-doped $\mathrm{TiO}_{2}$ of the present work has PM behaviour of small susceptibility $\left(\sim 10^{-7} \mathrm{cgs} / \mathrm{g}\right)$, as presented in Table:2. Similar behaviour was also observed earlier [38,39]. The PM properties were attributed to the created structural point defects, including O-vacancies. In general, the point defects can generate PM or weak FM properties [20] depending on their concentration, distribution, and separations.

The PM behaviour of $\mathrm{TiO}_{2}$ nano-powder in the present work maintained even with codoping. However, the incorporation of $\mathrm{Ni} / \mathrm{Al}$ ions in the host $\mathrm{TiO}_{2}$ caused a remarkable increase in the susceptibility by 10 times. The PM susceptibility of $\mathrm{TiO}_{2}: \mathrm{Ni}: \mathrm{Al}$ sample can be used to estimate the average effective para-magnetic moment per dopant $\mathrm{Ni}$ ion interacted paramagnetically with the applied field by using Curie law for mass susceptibility (per g): $\chi($ perg $)=N_{N i} \mu_{N i}^{2} / 3 \rho k_{B} T$, where, $\mu_{N i}$ is the para-magnetic moment per dopant $\mathrm{Ni}$ ion, $\mathrm{k}_{\mathrm{B}}$ is the Boltzmann constant, $\rho$ is the density of host $\mathrm{TiO}_{2}$, and $\mathrm{T}$ is the working temperature. Thus, $\mu_{\mathrm{Ni}}$ is equal to $3.38 \mu_{\mathrm{B}}$ for $\mathrm{TiO}_{2}: \mathrm{Ni}: \mathrm{Al}$, where $\mu_{\mathrm{B}}$ is the Bohr magneton. However, the known experimental paramagnetic moment of $\mathrm{Ni}(\mathrm{II})$ ion in some

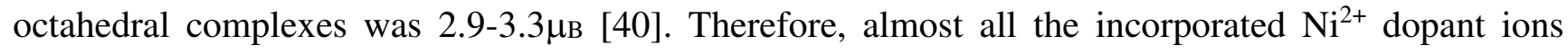
participated in the observed PM interaction. To attain the spin-spin S.S Heisenberg exchange interaction between dopant $\mathrm{Ni}^{2+}$ ions, the average interionic separation $(\mathrm{R})$ between them should be less than $(1.5 \times \mathrm{a})$, where (a) is the $\mathrm{TiO}_{2}$ lattice parameter [41,42] in addition to the proper local 
permittivity of the host $\mathrm{TiO}_{2}$ crystalline medium (ECM), which intermediate the $\boldsymbol{S} . \boldsymbol{S}$ interaction. For uniform distribution of $\mathrm{Ni}^{2+}$ dopant ions throughout the host $\mathrm{TiO}_{2}$ lattice, the average interionic separation $(\mathrm{R})$ can be estimated by; $N_{\text {ion }} V=1$, where $N_{\text {ion }}$ is the $\mathrm{Ni}^{2+}$ concentration $\left(1.37 \times 10^{21} \mathrm{~cm}^{-3}\right)$ and $\mathrm{V}=(4 / 3) \pi \mathrm{R}^{3}$, thus $\mathrm{R} \sim 0.56 \mathrm{~nm}$, which almost equal to $1.5 \times \mathrm{a}$. Moreover, the concentration of $\mathrm{Ni}^{2+}$ ions is much less than that of anatase unit cells, $C_{\text {cell }}=V_{\text {cell }}^{-1}=7.40 \times 10^{21} \mathrm{~cm}^{-3}$. Therefore, due to the distance separation between dopant $\mathrm{Ni}^{2+}$ ion, the $\boldsymbol{S} . \mathrm{S}$ interaction between neighbouring $\mathrm{Ni}^{2+}-\mathrm{Ni}^{2+}$ dopant ions could not be switched-on confirming the observed results unless stimulate the anatase ECM for the super-exchange interaction between the $\mathrm{Ni}^{2+}-\mathrm{Ni}^{2+}$ dopant ions. Such stimulation was successfully achieved in the present work by the hydrogenation process.

\section{2- Investigation of hydrogenated samples}

The magnetic study of the hydrogenated synthesized un-doped $\mathrm{TiO}_{2}-\mathrm{H}$ sample at room temperature (RT) revealed the creation of weak FM properties superimposed on the major DM behavior. The FM component of $\mathrm{TiO}_{2}-\mathrm{H}$ behavior is shown in Fig.3. Such a weak $\mathrm{d}^{0} \mathrm{FM}$ phenomenon (explained in the introduction) could be generated by the internal structural point defects, like O-vacancies, which mainly created by hydrogenation [20].

The FM parameters ( $\mathrm{H}_{\mathrm{c}}$ : coercive force, $\mathrm{M}_{\mathrm{r}}$ : remanence, and $\mathrm{M}_{\text {sat }}$ : saturation magnetization) extracted from hysteresis loops are given in table:2. Moreover, the magnetic energy ( $\mathrm{U}_{\mathrm{mag}}$ ) was calculated to compare the quality of the FM hysteresis behaviours for one magnetic system and considered as a figure-of-merit, $\mathrm{FOM}=\mathrm{U}_{\mathrm{mag}}=\mathrm{H}_{\mathrm{c}} \mathrm{M}_{\mathrm{r}}(\mathrm{erg} / \mathrm{g})$ [43]. The magnetic energy $\mathrm{U}_{\mathrm{mag}}$ of undoped $\mathrm{TiO}_{2}$ was weak $(0.12 \mathrm{erg} / \mathrm{g})$ and it is unstable and could be thermally removed.

It is clear that the hydrogenation has an amazing effect on the magnetic properties of SSS$\mathrm{TiO}_{2}: \mathrm{Ni}: \mathrm{Al}$, which under the impact of Ni dopant could create RT-FM through controlling over the $E C M$. The created FM parameters are presented in table:2. The $\mathrm{M}_{\text {sat }}$ values can be used to estimate the effective ferro-magnetic moment of dopant $\mathrm{Ni}^{2+}$ ions participated in the $\mathrm{FM}$ properties through the following equation: $\mu_{\mathrm{Ni}^{2+}}^{\text {eff }}=\mathrm{M}_{\text {sat }}(\mathrm{emu} / \mathrm{g}) \times \mathrm{D} / \mathrm{N}_{\mathrm{Ni}^{2+}}\left(\mathrm{cm}^{-3}\right)$, where D is the density of host $\mathrm{TiO}_{2}\left(4.23 \mathrm{~g} \cdot \mathrm{cm}^{-}\right.$

${ }^{3}$ ) and $\mu_{\mathrm{Ni}^{2+}}^{\text {eff }}$ is the effective FM moment of $N i^{2+}$ ions. Thus, $\mu_{\mathrm{Ni}^{2+}}^{\text {eff }}=0.37 \mu_{B}$, which is less than the known value $0.60 \mu_{\mathrm{B}}$ for the FM moment extracted from the saturation measurements of the pure Ni metal at RT. Thus, only $\sim 62 \%$ of the dopant $\mathrm{Ni}^{2+}$ ions could participate in the creation of FM behaviour. Such participation fraction is attributed to the nature of the synthesized nano-crystallites powder samples; some doped Ni ions were not Ferro-magnetically interacted with each other and might accumulate on the crystallite boundaries $(\mathrm{CBs})$ in the form of ions with different oxidation numbers. In general, the present experiments prove that such creation of FM is directly related to the created structural point defects like $\mathrm{O}$-vacancies and thus depends on the hydrogenation parameters. 
Under the impact of $\mathrm{Ni}^{2+}$ dopant ions, the $\mathrm{H}_{2}$ molecules, during the hydrogenation process, could be dissociated into hydrogen H-species [24]. The hydrogen acts as a reducing agent because it donates its electrons to the crystal creating structural O-vacancies, which assist the mediation of the superexchange $\boldsymbol{S} . \boldsymbol{S}$ interaction necessary for the realization of FM behavior. Thus, the hydrogenation that densifies the $\mathrm{O}$-vacancies and the itinerant electrons in $E C M$, is a necessary and sufficient condition to create FM properties at RT. Therefore, the strength of the created FM should be dependent on the hydrogenation conditions [the duration, $\Delta \mathrm{t}$, and temperature, $\mathrm{T}_{\mathrm{H}}$ ]. Consequently, the effect of the hydrogenation temperature $\mathrm{T}_{\mathrm{H}}$ on the strength of the created FM properties was studied in the present work by using two temperatures $\mathrm{T}_{\mathrm{H}}=400^{\circ} \mathrm{C}$ (for $\mathrm{H}$ sample) and $\mathrm{T}_{\mathrm{H}}=500{ }^{\circ} \mathrm{C}$ (for $\mathrm{HH}$ sample) and the obtained corresponding hysteresis loops are shown in fig.3.

Data of table:2 demonstrates that when the temperature $\mathrm{T}_{\mathrm{H}}$ increased by $100{ }^{\circ} \mathrm{C}$ (from $400^{\circ} \mathrm{C}$ to 500 ${ }^{\circ} \mathrm{C}$ ) then the $\mathrm{U}_{\mathrm{mag}}$ of $\mathrm{TiO}_{2}: \mathrm{Ni}: \mathrm{Al}$ system increased by 3.4 times and the $\mathrm{M}_{\text {sat }}$ increased by 1.4 times. So, the increase of $\mathrm{T}_{\mathrm{H}}$ causes an increase in the density of $\mathrm{O}$-vacancies, which, in turn, increases the "bridges of overlapping" between the spins $(\boldsymbol{S} . \boldsymbol{S})$ of the $\mathrm{Ni}^{2+}$ dopant ions. Therefore, the host $E C M$ plays a significant role in controlling the energy of the $\boldsymbol{S} . \boldsymbol{S}$ interaction.

Due to the procedure of the present work, especially the impact of Al co-dopant and apply suitable conditions of hydrogenation, the results of the created FM properties are very improved comparing to the results obtained by previous works. The saturation magnetization $\mathrm{M}_{\text {sat }}$ for $\mathrm{Ni}$-doped $\mathrm{TiO}_{2}$ was $0.044 \mathrm{memu} / \mathrm{g}$ [44], $0.020 \mathrm{emu} / \mathrm{g}$ [45], 0.021emu/g [46], and for ( $\mathrm{Ni}+\mathrm{Fe})$-codoped $\mathrm{TiO}_{2}$ sample the result was $0.160 \mathrm{emu} / \mathrm{g}$ [47].

\section{Conclusions}

Pristine and Ni/Al-codoped $\mathrm{TiO}_{2}$ nanocomposites were successfully synthesized by the thermal coprecipitation method to fabricate DMS solid solution (SSS) material. The structural and optical properties of the samples were systematically investigated to confirm the formation of SSS. Nickel dopant ions are used to introduce stable ferromagnetic (FM) properties for the synthesized anatase nano-powder sample, while the aluminum dopant ions are utilized to supply itinerant electrons necessary to support and boost the created FM properties. The samples were hydrogenized at two temperatures $\left(400{ }^{\circ} \mathrm{C}\right.$ and $500{ }^{\circ} \mathrm{C}$ ). Thus, the studied nanocomposite samples were: $\mathrm{TiO}_{2}, \mathrm{TiO}_{2}: \mathrm{Ni}: \mathrm{Al}$, $\mathrm{TiO}_{2}-\mathrm{H}, \mathrm{TiO}_{2}: \mathrm{Ni}: \mathrm{Al}-\mathrm{H}$, and $\mathrm{TiO}_{2}: \mathrm{Ni}: \mathrm{Al}-\mathrm{HH}$. The effect of hydrogenation temperature on the created FM parameters especially the magnetic energy $\left(U_{\text {mag }}\right)$ and saturation magnetization $\left(M_{\text {sat }}\right)$ was the purpose of the present study. Novel results about the boosting of the created FM were obtained by using a suitable hydrogenation temperature $\left(\mathrm{T}_{\mathrm{H}}\right)$. The values of $1.09 \mathrm{emu} / \mathrm{g}$ for $\mathrm{M}_{\text {sat }}$ and $42.6 \mathrm{erg} / \mathrm{g}$ for magnetic energy $\left(\mathrm{U}_{\mathrm{mag}}\right)$ were achieved when $\mathrm{T}_{\mathrm{H}}=500{ }^{\circ} \mathrm{C}$. These values are higher by $\sim 50$ times than those obtained for previous investigations on Ni-doped $\mathrm{TiO}_{2}$. The experimental Data revealed that 
$\mathrm{U}_{\text {mag }}$ of the hydrogenated $\mathrm{TiO}_{2}: \mathrm{Ni}: \mathrm{Al}$ system increased by $241 \%$ and the magnetization increased by $140 \%$ with increasing of $\mathrm{T}_{\mathrm{H}}$ by $100{ }^{\circ} \mathrm{C}\left(400{ }^{\circ} \mathrm{C}-\right.$ to $\left.-500^{\circ} \mathrm{C}\right)$.

Such great novel results obtained due to two factors: using $\mathrm{Al}^{3+}$ ions co-doping as a supplier of itinerant electrons that boost the $\boldsymbol{S} . \boldsymbol{S}$ Heisenberg interactions and choosing the appropriate temperature of hydrogenation.

\section{No conflict of interest exists:}

I wish to confirm that there are no conflicts of interest associated with this publication and there has been no significant financial support for this work that could have influenced its outcome.

\section{Caption of tables}

Table:1 lattice microstrain $(\varepsilon)$, Crystallite size (CS), Lattice parameters ( $a=b$ and c), unit-cell volume ( $\left.\mathrm{V}_{\text {cell }}\right)$, Rietveld refinement parameters, $\mathrm{RP}\left(\mathrm{R}_{\mathrm{wp}}\right.$ and $\left.\mathrm{S}\right)$, and threshold optical absorption ( $\left.\mathrm{E}_{\mathrm{th}}\right)$ of the synthesized nanocomposite powders.

Table:2 Magnetic parameters of the synthesized nanocomposite powders; PM susceptibility $(\chi)$ and FM parameters $\left(\mathrm{H}_{\mathrm{c}}\right.$ : coercive force, $\mathrm{M}_{\mathrm{r}}$ : remanence, $\mathrm{M}_{\mathrm{s}}$ : saturation magnetisation, and magnetic energy, Umag.)

\section{Caption of figures}

Fig.1a: XRD patterns of the synthesized nanopowders; TiO2, TiO2:Ni:Al, TiO2-H, TiO2:Ni:Al-H, and TiO2:Ni:Al-HH. Anatase is the major phase crystallised.

Fig.1b: Graphical representation of the Rietveld refinements for $\mathrm{TiO}_{2}: \mathrm{Ni}: \mathrm{Al}$ sample, where; the red solid line (up) is the experimental data, the blue solid line (up) is the calculated pattern, and the solid pink line (down) is the intensity difference between the calculated and registered.

Fig.1c: $\mathrm{H}-\mathrm{W}$ plot for $\mathrm{TiO}_{2}: \mathrm{Ni}: \mathrm{Al}$ sample

Fig.2: Spectral K-M absorption function; $F(\lambda)$ of the hydrogenated samples. The thresholds of absorption are shown. The inset shows is the function absorption function $F(\lambda)$ of the synthesized samples $\left(\mathrm{TiO}_{2}\right.$ and $\left.\mathrm{TiO}_{2}: \mathrm{Ni}: \mathrm{Al}\right)$

Fig.3: $\mathrm{M}(\mathrm{H})$ relationship for the hydrogenated samples. 
Table 1:

\begin{tabular}{|c|c|c|c|c|c|c|c|}
\hline \multirow{2}{*}{ Sample } & \multirow{2}{*}{$\varepsilon(\%)$} & \multirow{2}{*}{$\mathrm{CS}(\mathrm{nm})$} & \multirow{2}{*}{$\mathrm{a}, \mathrm{b}, \mathrm{c}(\AA)$} & \multirow{2}{*}{$\mathrm{V}_{\text {cell }}\left(\AA^{3}\right)$} & \multicolumn{2}{|c|}{ R.P } & \multirow[b]{2}{*}{$\mathrm{E}_{\mathrm{th}}(\mathrm{eV})$} \\
\hline & & & & & $\mathrm{R}_{\mathrm{wp}}(\%)$ & $S$ & \\
\hline $\mathrm{TiO}_{2}$ & 0.03 & 5.8 & $a=b=3.7732, \quad c=9.484$ & 135.02 & 27.7 & 1.30 & 3.10 \\
\hline $\mathrm{TiO}_{2}: \mathrm{Ni}: \mathrm{Al}$ & 0.7 & 6.8 & $\mathrm{a}=\mathrm{b}=3.774,, \mathrm{c}=9.460$ & 134.7 & 29.76 & 1.16 & 2.70 (vis) \\
\hline \multicolumn{8}{|c|}{ Hydrogenated samples } \\
\hline $\mathrm{TiO}_{2}-\mathrm{H}$ & $\sim 0$ & 4.8 & $a=b=3.779, \quad c=9.499$ & 135.7 & 25.39 & 1.45 & 3.17 \\
\hline $\mathrm{TiO}_{2}: \mathrm{Ni}: \mathrm{Al}-\mathrm{H}$ & 0.7 & 6.9 & $\mathrm{a}=\mathrm{b}=3.780, \quad \mathrm{c}=9.460$ & 135.1 & 25.21 & 1.22 & 3.28 \\
\hline $\mathrm{TiO}_{2}: \mathrm{Ni}: \mathrm{Al}-\mathrm{HH}$ & $\sim 0.0$ & 5.8 & $a=b=3.784, \quad c=9.482$ & 135.7 & 26.35 & 1.28 & 3.28 \\
\hline
\end{tabular}

Table:2

\begin{tabular}{|c|c|c|c|c|c|}
\hline Sample & Behaviour & $\mathrm{H}_{\mathrm{c}}(\mathrm{Oe})$ & $\mathrm{M}_{\mathrm{r}}(\mathrm{memu} / \mathrm{g})$ & $\mathrm{M}_{\mathrm{sat}}(\mathrm{memu} / \mathrm{g})$ & $\mathrm{U}_{\mathrm{mag}}(\mathrm{erg} / \mathrm{g})$ \\
\hline $\mathrm{TiO}_{2}-\mathrm{H}$ & DM+ Weak FM & 185.7 & 0.5 & 2.2 & 0.09 \\
\hline $\mathrm{TiO}_{2}: \mathrm{Ni}: \mathrm{Al}-\mathrm{H}$ & FM & 54.6 & 228.6 & 781.5 & 12.48 \\
\hline $\mathrm{TiO}_{2}: \mathrm{Ni}: \mathrm{Al}-\mathrm{HH}$ & FM & 107.3 & 397.2 & 1092.1 & 42.60 \\
\hline & & $\chi(\mathrm{cgs} / \mathrm{g})$ & & & \\
\hline $\mathrm{TiO}_{2}$ & Weak PM & $3.4 \times 10^{-7}$ & & & \\
\hline $\mathrm{TiO}_{2}: \mathrm{Ni}: \mathrm{Al}$ & PM & $2.62 \times 10^{-6}$ & & & \\
\hline
\end{tabular}




\section{References}

[1] N. Rahimi, R. A.Pax, E. Mac. A.Gray, Review of functional titanium oxides. $\mathrm{I} \mathrm{TiO}_{2}$ and its modifications, Progress in solid state chemistry 44(3)(2016) 86-105., https://doi.org/10.1016/j.progsolidstchem.2016.07.002

[2] D. Reyes-Coronado, G. Rodriguez-Gattorno, M. E. Espinosa-Pesqueira, C. Cab, R. de Coss and G. Oskam, Phase-pure TiO2 nanoparticles: anatase, brookite and rutile, Nanotechnology 19 (2008) 145605 (10pp)

[3] A. Balhamri, A. Deraoui, Y. Bahou, M. Rattal, Az. Mouhsen, M. Harmouchi, A. Tabyaoui and E. M. Oualim, Surface and optical properties of zinc oxide doped with fluor synthesized by magnetron sputtering: applications in transparent conductive oxides (TCO), Int. J. Thin. Fil. Sci. Tec. 4(3)(2015) 205-210， http://dx.doi.org/10.12785/ijtfst/040308

[4] J. Dong, J. Han,Y. Liu, A. Nakajima, S. Matsushita, S. Wei, W. Gao, Defective black $\mathrm{TiO}_{2}$ synthesized via anodization for visible-light photocatalysis.

Appl. Mater. Inter. 6 (2018)1385-1388.

[5] D. V. Bavykin,V. N. Parmon, A. A. Lapkin, F. C. Walsh, The effect of hydrothermal conditions on the mesoporous structure of $\mathrm{TiO}_{2}$ nanotubes.

J. Mater. Chem. 14 (2004) 3370-3377.

[6] H. -F. Zhuang, C. -J. Lin, Y. -K. Lai, L. Sun, J. Li, Some Critical Structure Factors of Titanium Oxide Nanotube Array in Its Photocatalytic Activity, Environ. Sci. Technol. 41 (2007) 4735- 4740.

[7] Xuefeng Lu, Tingting Zhao, Xu Gao, Junqiang Ren, Xiaobin Yan, and Peiqing La, Investigation of Mo-, Pt-, and $\mathrm{Rh}$-doped rutile $\mathrm{TiO}_{2}$ based on first-principles calculations, AIP Advances 8 (2018) 075014; https://doi.org/10.1063/1.5038776

[8] Y. Ma, X. Wang, Y. Jia, X. Chen, H. Han, C. Li, Titanium dioxide-based nanomaterials for photocatalytic fuel generations,Chem. Rev. 114 (2014) 9987-10043.

[9] J. Tian, H. Gao, H. Deng, L. Sun, H. Kong, P. Yang, J. Chu, Structural, magnetic and optical properties of Ni-doped $\mathrm{TiO}_{2}$ thin films deposited on silicon( $\left(\begin{array}{lll}1 & 0 & 0\end{array}\right)$ substrates by sol-gel process , J. Alloys Compd. 581 (2013) 318-323.

[10] M. Manzoor, A. Rafiq, M. Ikram, M. Nafees, S. Ali, Structural, optical, and magnetic study of $\mathrm{Ni}$-doped $\mathrm{TiO}_{2}$ nanoparticles synthesized by sol-gel method, Int. Nano Letters 8 (2018)1-8.

[11] X. Chen, S. S. Mao, Titanium dioxide nanomaterials: synthesis, properties, modifications, and applications. Chem. Rev. 107 (2007) 2891-2959

[12] U. Diebold, The surface science of titanium dioxide. Surf. Sci. Rep. 48(2003) 53-229.

[13] A. C. M. Padilha, H. Raebiger, A. R. Rocha and G. M. Dalpian, Charge storage in 
oxygen deficient phases of $\mathrm{TiO}_{2}$ : defect Physics without defects,

Sci. Rep. 6 - 28871(2016)1-6.

[14] Y. Xu, C. Zhang, L. Zhang, X. Zhang, H. Yao, J. Shi, Pd-catalyzed instant hydrogenation of $\mathrm{TiO}_{2}$ with enhanced photocatalytic performance Energy,

Environ. Sci. Technol. 9 (2016) 2410-2417

[15] Mohamed Bououdina, Aqeel Aziz Dakhel, Mohammad El-Hilo, Dalaver H. Anjum, Mohammed Benali Kanoun, and Souraya Goumri-Said, Revealing a room temperature ferromagnetism in cadmium oxide nanoparticles: an experimental and first-principles study, RSC Adv. 5 (2015) 33233-33238.

[16] B. Qi, S. Olafsson and H. P. Gislason, Vacancy defect-induced d0 ferromagnetism in undoped $\mathrm{ZnO}$ nanostructures: Controversial origin and challenges, Prog. Mater. Sci. 90 (2017) 45-74.

[17] G. Feng, W. Shufen, C. Hongming, L. Chunzhang, Synthesis and optical properties of $\mathrm{SnO}_{2}$ nanorods, Nanotechnology 19 (2008) 095708.

[18] S. Kumar, Y. J. Kim, B. H. Koo, S. Gautam, K. H. Chae, R. Kumar, C. G. Lee, Room temperature ferromagnetism in chemically synthesized ZnO rods,Mater. Lett. 63 (2009) 194-196.

[19] I. S. Elfimov, S. Yunoki, G. A. Sawatzky, Possible Path to a New Class of Ferromagnetic and Half-Metallic Ferromagnetic Materials, Phys. Rev. Lett. 89 (2002) 216403.

[20] S. Zhou, E. Cizmar, K. Potzger, M. Krause, G. Talut,M. Helm, J. Fassbender, S. A. Zvyagni, J. Wasnitza, H. Schmidt, Origin of magnetic moments in defective TiO2 single crystals, Phys. Rev. B 79 (2009) 113201.

[21] A. A. Dakhel, M. Bououdina, Structural, optical, and magnetic properties of $\mathrm{Cu}$ - and $\mathrm{Ni}$-codoped $\mathrm{CdO}$ dilute magnetic nanocrystalline semiconductor: effect of hydrogen post- treatment, Appl. Phys. A 119 (2015)1053-1060.

[22] A. A. Dakhel, Critical role of hydrogenation for creation of magnetic $\mathrm{Cd}-\mathrm{Cu}$ co-incorporated $\mathrm{TiO}_{2}$ nanocrystallites, Applied Physics A 126 (2020) 41 (8 pages).

[23] R. D. Shannon, Revised effective ionic radii and systematic studies of interatomic distances in halides and chalcogenides, Acta Crystallogr. A 32 (1976) 751-767.

[24] M. Pozzo, D. Alfe, Hydrogen dissociation and diffusion on transition metal (=Ti, Zr, V, Fe, Ru, Co, Rh, Ni, Pd, Cu, Ag)-doped Mg (0001) surface, Int. J. Hydrogen Energy 34 (2009) 1922 - 1930.

[25] S. M. Gupta, M. Tripathi, A review of $\mathrm{TiO}_{2}$ nanoparticles, Chinese Sci. Bulletin 56 (2011) 1639-1657. DOI: 10.1007/s11434-011-4476-1

[26] P. W. Atkins, T. L. Overton, J. P. Rourke, M. T. Waller, F. A. Armstrong, Inorganic Chemistry, $5^{\text {th }}$ ed., University press-Oxford, OX2 6DP, UK, 2010, 
Web: Inorganic Chemistry - Mark Weller, Tina Overton, Jonathan Rourke, Fraser Armstrong - Google Books.mht

[27] L. B. McCusker, R. B. Von Dreele, D. E. Cox, D. Louer, P. Scardi, Rietveld refinement guidelines, J. Appl. Cryst. 32 (1999) 36.

[28 ] A. Khorsand Zak, W. H. Abd Majid, M. E. Abrishami, R. Yousefi, X-ray analysis of $\mathrm{ZnO}$ nanoparticles by Williamson-Hall and size-strain plot methods,

Solid State Sci. 13 (2011) 251-256.

[29] A. E. Morales, E. S. Mora, and U. Pal, Use of diffuse reflectance spectroscopy for optical characterization of un-supported nanostructures, Revista Mexicana de Fisica S53 (2007) 18-22.

[30] Daniela Sojic, Vesna Despotovic, Biljana Abramovic, Nadia Todorova, Tatiana Giannakopoulou, and Christos Trapalis, Photocatalytic degradation of mecoprop and clopyralid in aqueous suspensions of nanostructured $\mathrm{N}$-doped $\mathrm{TiO}_{2}$, Molecules 15 (2010) 2994-3009; doi:10.3390/molecules15052994.

[31] F. N. C. Anyaegbunam, C. Augustine, A study of optical gap associated Urbach energy tail of chemically deposited metal oxides binary films, Dig. J. Nanomater. Bios.13 (2018) 847-856.

[32] S. C. Baker-Finch, K. R. McIntosh, Di Yan, K. C. Fong, Near-infrared free carrier absorption in heavily doped silicon, J. Appl. Phys. 116 (2014) 063106 (12 pages).

[33 ] A. A. Dakhel, A. Y. Ali-Mohamed, Optical and transport phenomena in CdO: La films prepared by sol-gel method, J. Sol-Gel Sci. Technol. 44 (2007) 241-247

[34] H. L. Hartnagel, A. L. Dawar, A. K. Jain, G. Jagadish, Semiconducting Transparent Thin Films, IOP, Bristol, 1995.p. 226.

[35] Z. Qiao, C. Agashe, D. Mergel, Dielectric modeling of transmittance spectra of thin ZnO:Al Films, Thin Solid Films 496, 520 (2006).

[36] Le Yuan, Xiaolong Weng, Ming Zhou, Qingyong Zhang, and Longjiang Deng, Structural and Visible-Near Infrared Optical Properties of Cr-Doped $\mathrm{TiO}_{2}$ for Colored Cool Pigments, Nanoscale Res Lett. 12, 597 (2017). doi: 10.1186/s11671-017-2365-5

[37] S. C. Baker-Finch, K. R. McIntosh, Di Yan, K. C. Fong, Near-infrared free carrier absorption in heavily doped silicon, J. Appl. Phys. 116 (2014) 063106 (12 pages).

[38] H. Wang, J. Wei, R. Xiong, J. Shi, Enhanced ferromagnetic properties of Fe+N codoped TiO2 anatase, J. Magn. Magn. Mater 324 (2012) 2057-2061.

[39] Anand Kumar, Manish K. Kashyap, Namita Sabharwal, Sarvesh Kumar, Ashok Kumar, Parmod Kumar, K. Asokan, Structural, optical and weak magnetic properties of Co and Mn codoped TiO2 nanoparticles, Solid State Sciences 73 (2017) 19-26.

[40] The web page of the University of the West Indies at Mona, Jamaica, The Dept. of Chemistry, http://wwwchem.uwimona.edu.jm/spectra/MagMom.html. accessed May. 2020. 
[41] L. Bergqvist, O. Eriksson, J. Kudrnovsky, V. Drchal, P. Korzhavyi, L. Turek, Magnetic Percolation in Diluted Magnetic Semiconductors, Phys. Rev. Lett. 93(2004) 137202.

[42] S. -Y. Seo, C. -H. Kwak, S. -H. Kim, S. -H. Park, I. -J. Lee, S .-W. Han, Synthesis and characterization of ferromagnetic Zn1-xCoxO films, J. Cryst. Growth 346 (2012) 56.

[43] V. Raghavan, Materials Science and Engineering: A first course, 5th ed., 2004, Prentic-Hall of India private limited, New Delhi, P.406.

[44] Sandeep Kumar Singh Patel, Paramananda Jena, N.S. Gajbhiye, Structural and roomtemperature ferromagnetic properties of pure and $\mathrm{Ni}$-doped $\mathrm{TiO}_{2}$ nanotubes, Materials Today: Proceedings 15 (2019) 388-393

[45] Qing Wang, Xiaoming Liu, Xuegang Wei, Jianfeng Dai, and Weixue Li, Ferromagnetic Property of Co and Ni Doped $\mathrm{TiO}_{2}$ Nanoparticles, J. Nanomater., Volume 2015, Article ID 371582, 5 pages, http://dx.doi.org/10.1155/2015/371582

[46] M. Manzoor, A. Rafiq, M. Ikram, M. Nafees, S. Ali, Structural, optical, and magnetic study of $\mathrm{Ni}$-doped TiO2 nanoparticles synthesized by sol-gel method, Int. Nano Lett. 8 (2018)1-8.

[47] Salma Waseem, Safia Anjum, Lubna Mustafa, Tallat Zeeshan, Zohra Nazir Kayani, Khalid Javed, Structural, magnetic and optical investigations of $\mathrm{Fe}$ and $\mathrm{Ni}$ co-doped $\mathrm{TiO}_{2}$ dilute magnetic semiconductors, Cer. Int. 44 (2018) 17767-17774 


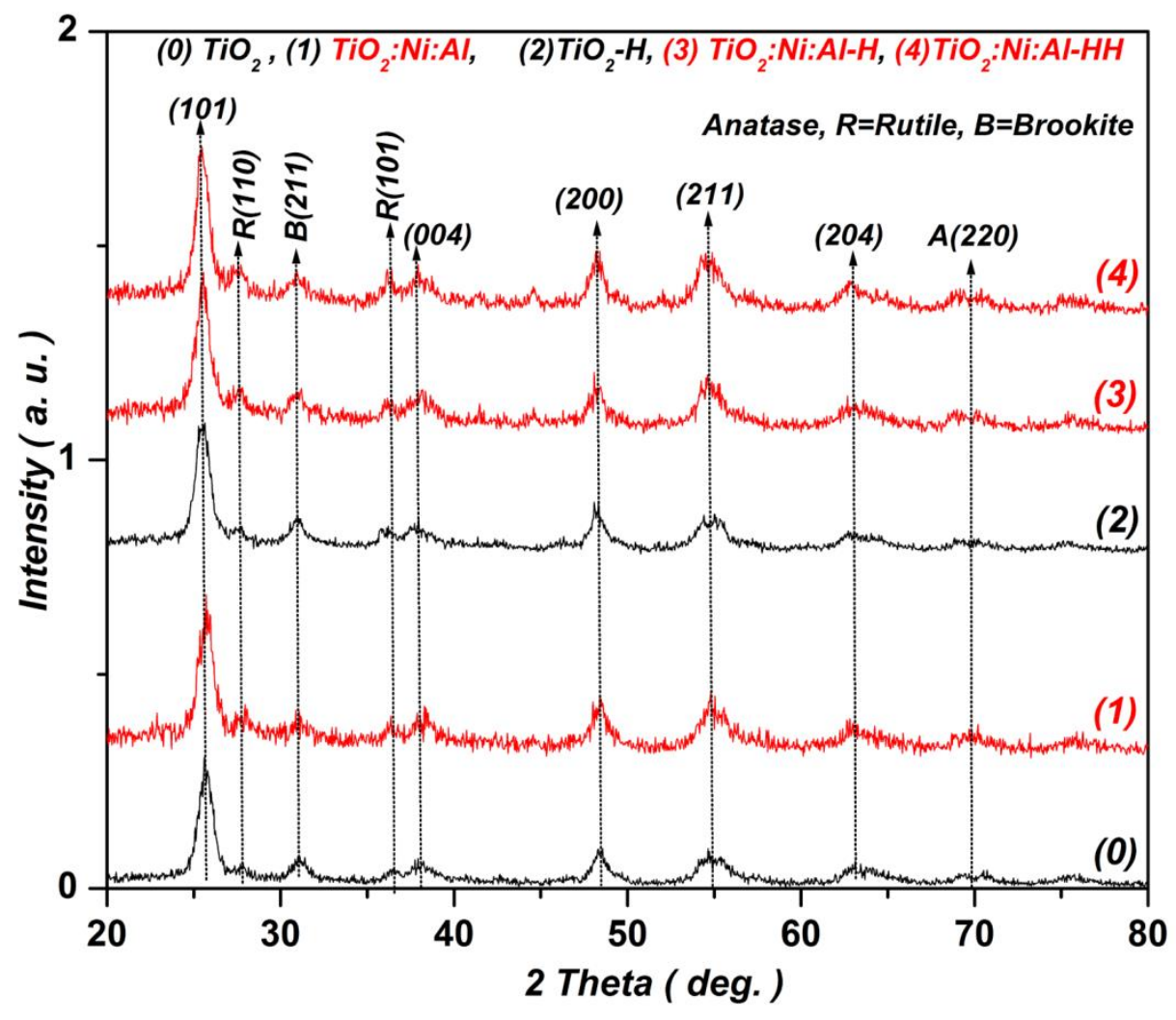

Fig.1a 


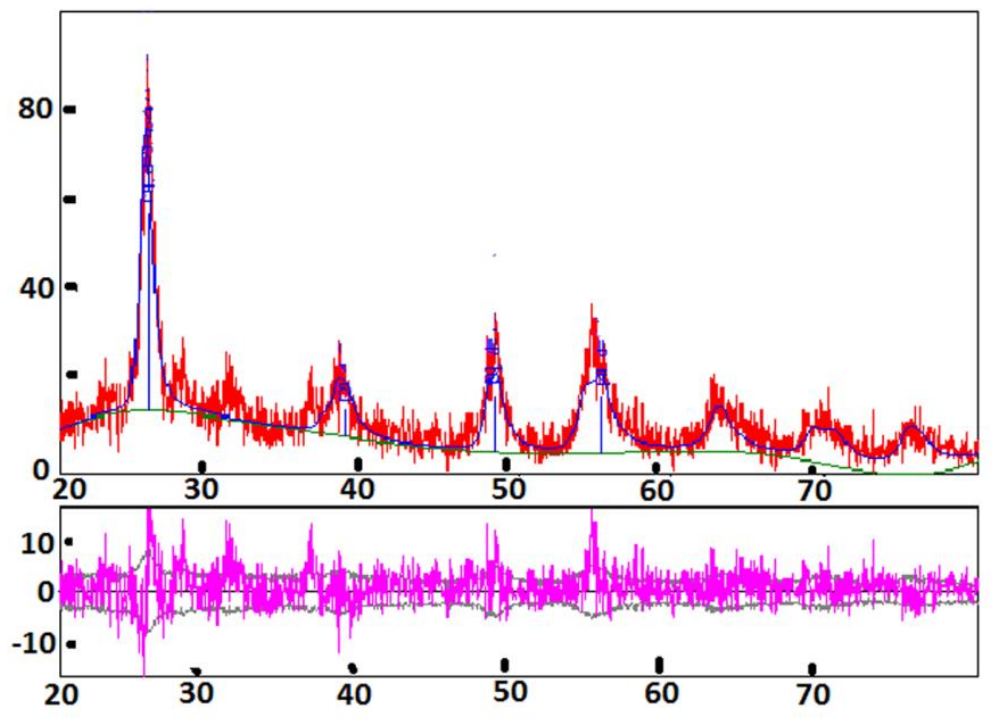

Fig.1b

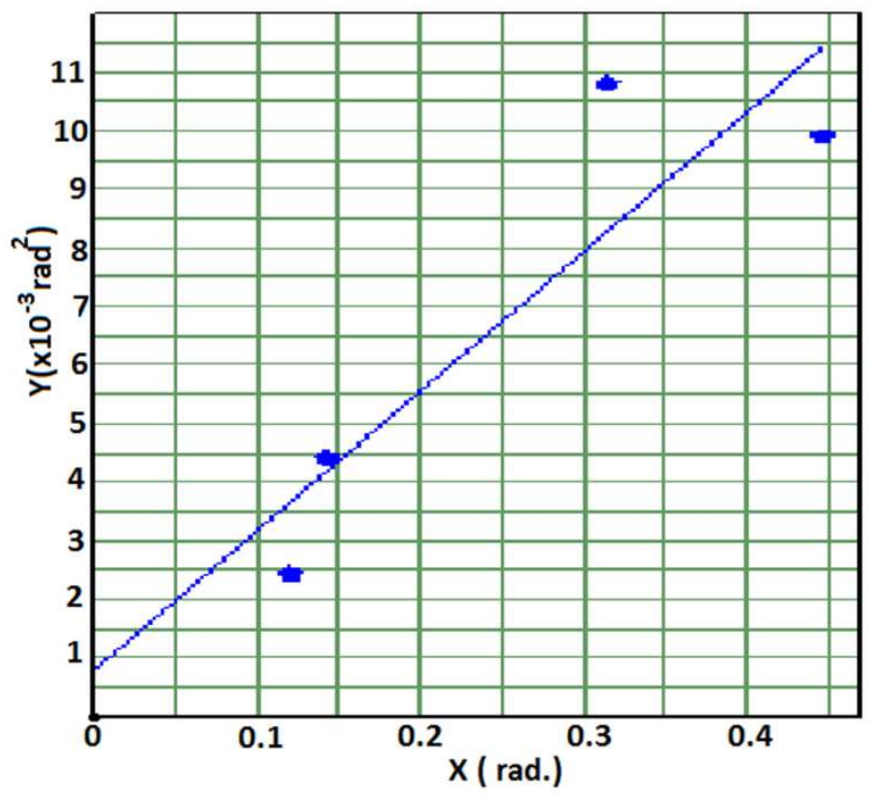

Fig.1c 
Fig. 2

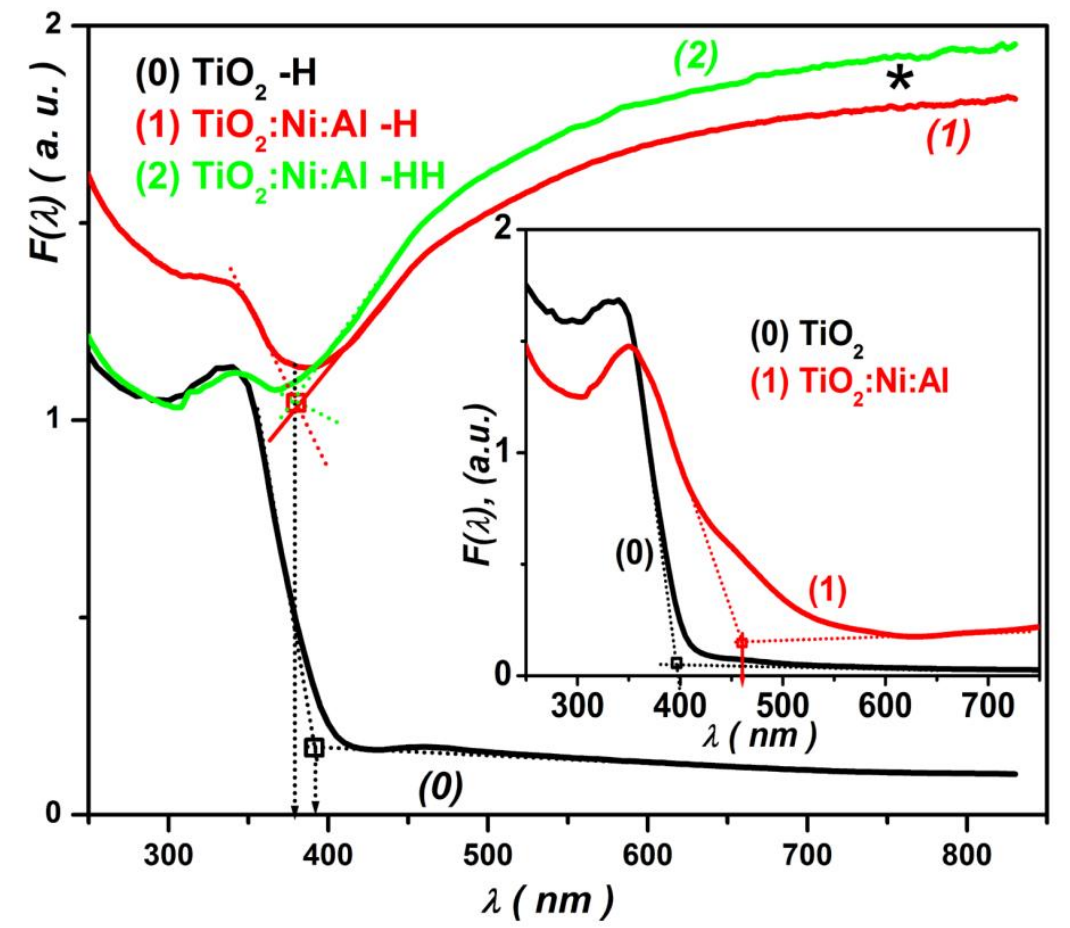

Fig. 3

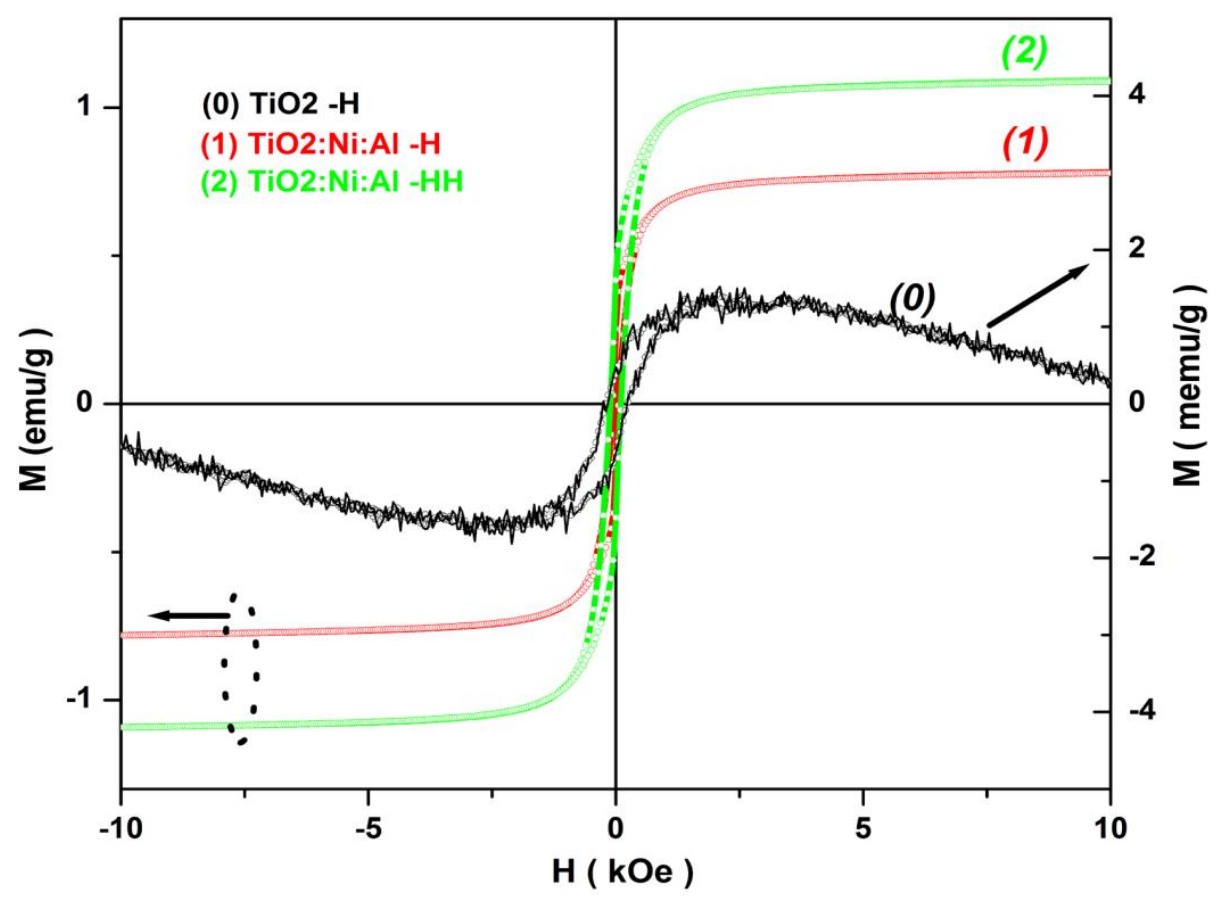


Figures
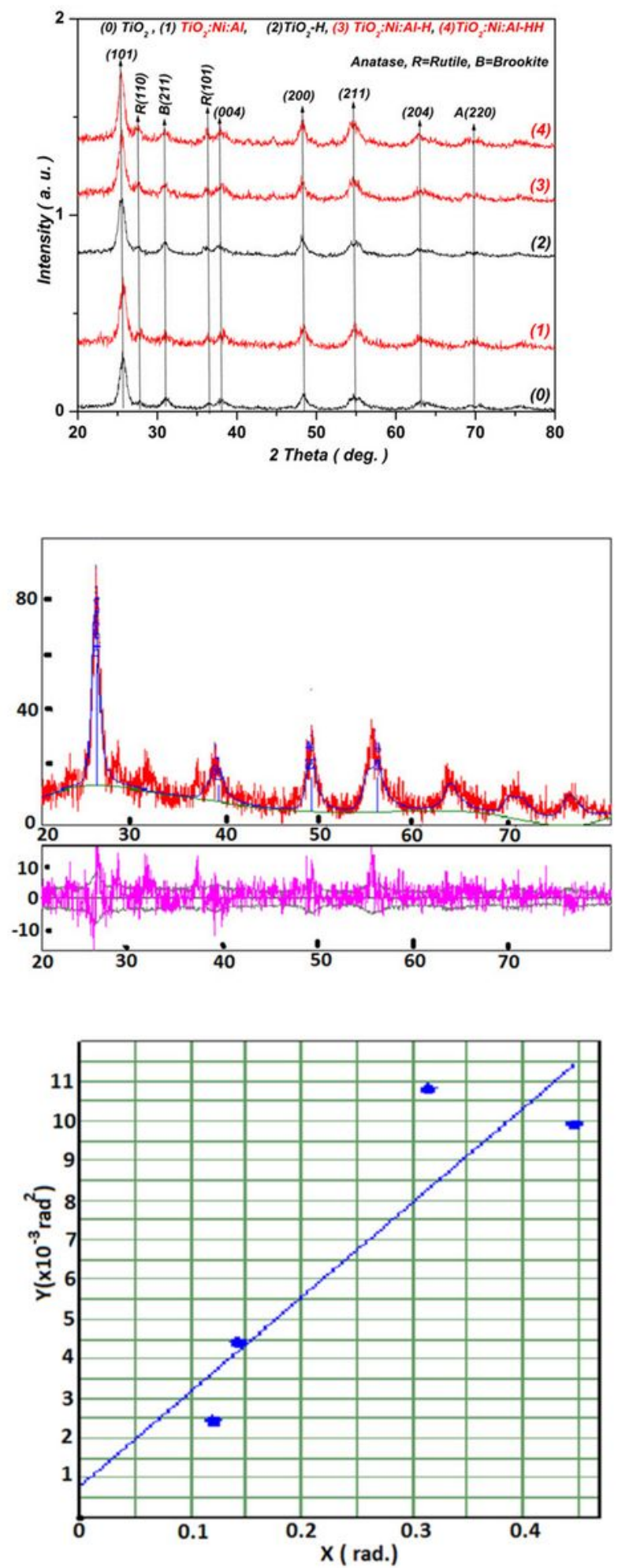

\section{Figure 1}

(Top) a: XRD patterns of the synthesized nanopowders; TiO2, TiO2:Ni:Al, TiO2-H, TiO2:Ni:Al-H, and TiO2:Ni:Al-HH. Anatase is the major phase crystallised. (Middle) b: Graphical representation of the Rietveld refinements for TiO2:Ni:Al sample, where; the red solid line (up) is the experimental data, the blue 
solid line (up) is the calculated pattern, and the solid pink line (down) is the intensity difference between the calculated and registered. (Bottom) c: H-W plot for TiO2:Ni:Al sample

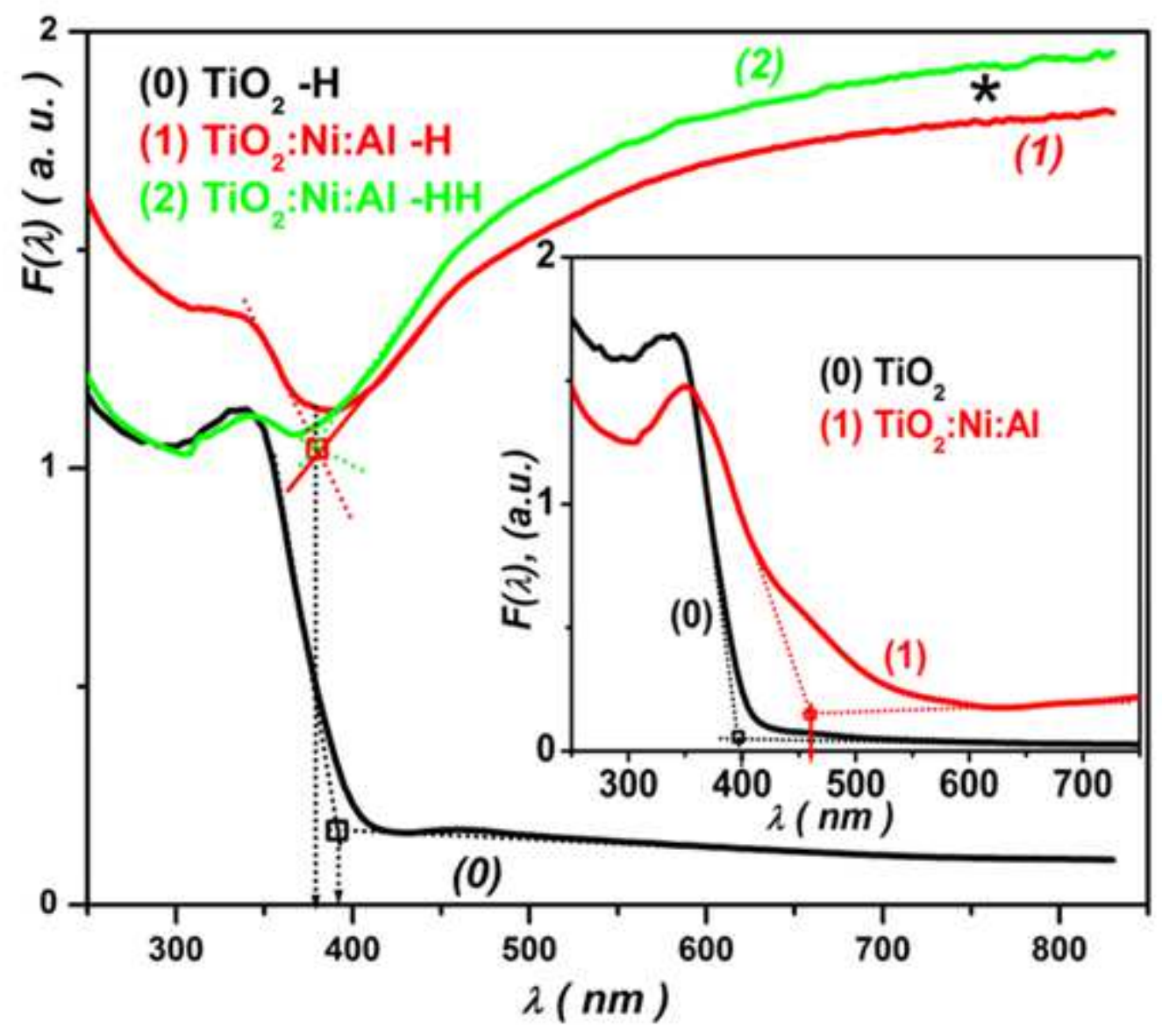

Figure 2

Spectral K-M absorption function; $F(\square)$ of the hydrogenated samples. The thresholds of absorption are shown. The inset shows is the function absorption function $\mathrm{F}(\square)$ of the synthesized samples (TiO2 and TiO2:Ni:Al) 


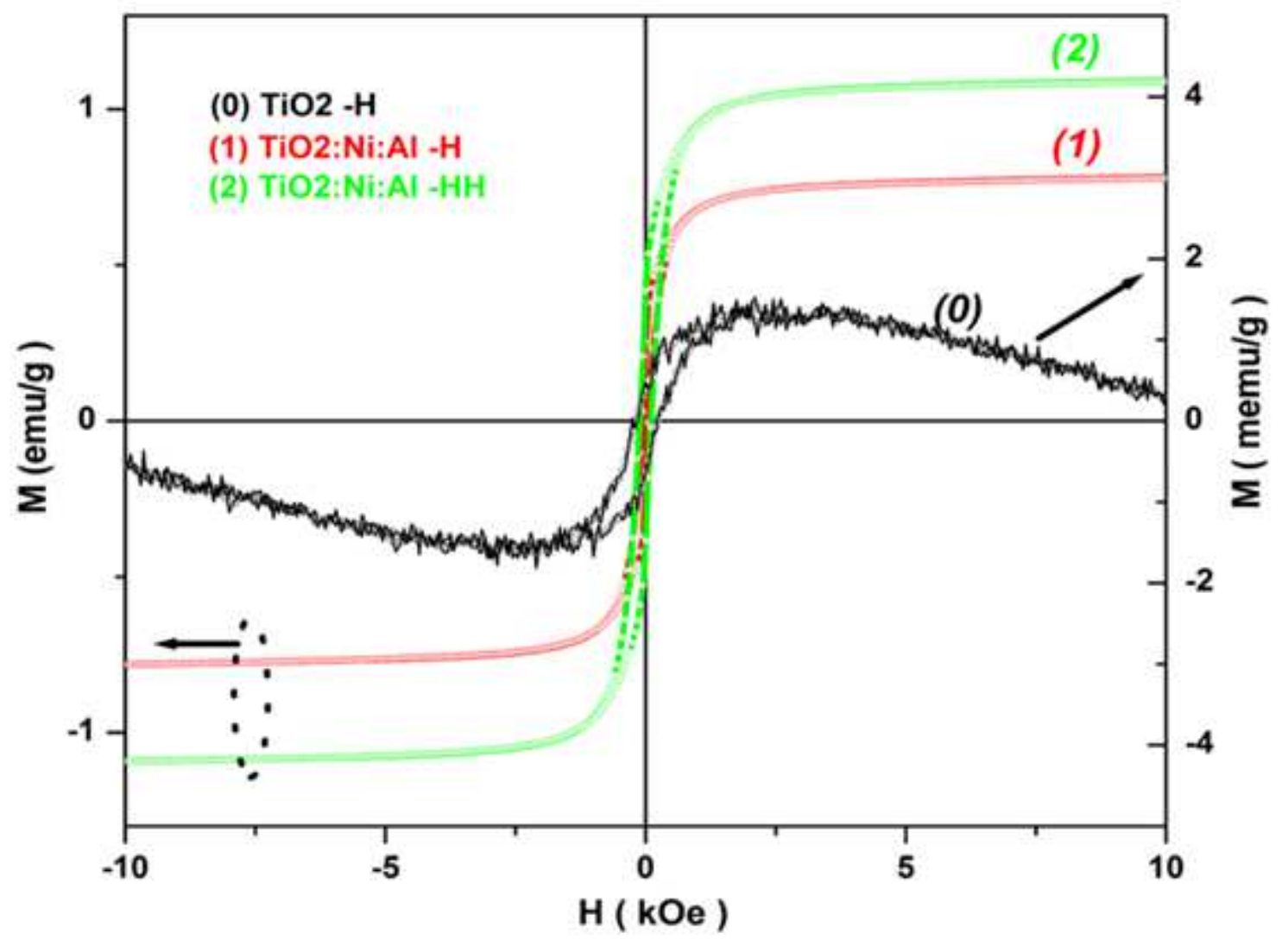

Figure 3

$M(H)$ relationship for the hydrogenated samples. 